\title{
A management perspective to using Public Participation GIS in planning for visitor use in national parks
}

Miisa Pietiläa* Nora Fagerholm ${ }^{\mathrm{b}, \mathrm{c}}$

${ }^{a *}$ Geography Research Unit, University of Oulu, Finland

${ }^{b}$ Department of Geography and Geology, University of Turku, Finland

${ }^{c}$ Department of Built Environment, Aalto University, Finland

a* Geography Research Unit, University of Oulu, Pentti Kaiteran katu 1, 90014, Oulu, Finland, e-mail: miisa.pietila@oulu.fi, tel.: +358 505993709

bepartment of Geography and Geology, University of Turku, FI-20014, Turku, Finland

cDepartment of Built Environment, PL 14100, 00076, Aalto, Finland

Accepted for publication in the Journal of Environmental Planning and Management (1.5.2018) 


\title{
A management perspective to using Public Participation GIS in planning for visitor use in national parks
}

\begin{abstract}
Academics have frequently used and endorsed the Public Participation GIS approach for national park management. However, it is only minimally used by public agencies such as national park organisations. This study explores the potential that managers of Finnish national parks see in the PPGIS approach in the context of planning for the visitor use of parks. Ten semi-structured interviews with managers of Parks and Wildlife Finland were conducted. The managers perceived that PPGIS could help in optimising site management, and preferred PPGIS studies that are practical and clearly connected to planning site management actions. They envisioned a mobile phone application that would allow mapping visitor experiences on the spot. Overall, the managers were open to adopting place-based planning practices. The study increases the understanding of public agencies' views towards PPGIS. It also produces practical information for conducting PPGIS case studies as well as for integrating PPGIS tools into planning processes.
\end{abstract}

Keywords: PPGIS; park manager; visitor management; outdoor recreation; Finland

\section{Introduction}

National parks worldwide are established to preserve biodiversity and the natural environment and to provide opportunities for quality visitor experiences (Frost and Hall 2009). To aid in this complex task, academics have promoted methods and frameworks which could improve the performance of park organisations. One approach that has recently been emphasised is Public Participation Geographic Information Systems (PPGIS). The aim of PPGIS approaches is to systematically and geographically map people's place-based experiences and integrate these into decision-making (Panek 2016). Many empirical studies using PPGIS methods have been conducted, often listing the advantages of PPGIS and recommending it for environmental planning practices (see e.g. reviews by Brown and Kyttä 2014; Brown and Fagerholm 2015). The focus of 
most PPGIS studies so far has been on holistic management and consolidation of different kinds of social values or land use values (such as recreational, spiritual, economic, aesthetic) (e.g. Brown, Weber and de Bie 2014; Garcia-Martin et al. 2017; Ives and Kendal 2014; van Riper et al. 2017; Scolozzi et al. 2014; Strickland-Munro et al. 2016; Palomo et al. 2014). Some studies have particularly addressed PPGIS in the context of outdoor recreation (Brown and Weber 2011; Beeco and Brown 2013; De Valck et al. 2016; Korpilo et al. 2018; Pietilä and Kangas 2015; Pietilä and Fagerholm 2016; Wolf et al. 2015; Wolf, Brown and Wohlfart 2017).

The decision-support potential of PPGIS has mostly been described in academic literature, and there is only little evidence of formal agency adoption beyond preliminary PPGIS trials (Brown 2012; Brown and Kyttä 2014; Kahila-Tani et al. 2016; Brown and Kyttä 2018). The explanations as to why regional and environmental planning agencies in Western counties have not adopted PPGIS methods in their planning processes often point to a lack of government commitment to public participation and consultation in general as well as to the absence of skills and institutional motivation to use the data effectively (Brown 2012; Brown and Kyttä 2014; Kahila-Tani et al. 2016). However, these issues are researchers' interpretations of the impediments and there is a lack of studies investigating managers' motivation and readiness to adopt the methods. Therefore, to promote the spread of the PPGIS approach from academia to practise, it is important to study the impediments to the adoption of PPGIS in the public sector, which indeed is listed as one of the research priorities related to PPGIS (Brown and Kyttä 2014; Brown and Kyttä 2018).

In this study, we assess the potential of PPGIS approaches from the managers' perspective in the context of visitor use planning in one of Finland's national parks, Oulanka National Park. The study design is unique to PPGIS studies, as it is based on 
personal interviews of managers and planners of Parks and Wildlife Finland, which is a unit of the state-run enterprise Metsähallitus and administrates the 40 national parks in Finland. The aim is to increase the understanding of how the PPGIS method could aid the planning for visitor use in parks and related recreation areas. Our first research question is How do the managers of Parks and Wildlife Finland plan the visitor use of national parks, and how could place-based information on visitor experiences support these planning practices? Secondly, we ask How would managers prefer implementing place-based monitoring of visitor experiences? The third research question is What are the attitudes of the managers with respect to place-based planning practices? Studying these issues in the Finnish context is relevant because although Finland is globally one of the pioneers in adopting PPGIS, it has nevertheless been shown that impediments to adopting place-based tools exist in Finland as well (Kahila-Tani et al. 2016).

Our study contributes to the PPGIS literature from two perspectives. First, it increases the knowledge on the possibilities of using the approach in the context of outdoor recreation planning. Secondly, the study discusses the actual applicability of the PPGIS approach, whereas many previous PPGIS studies only describe the use of PPGIS in a particular contexts.

\subsection{Planning for Visitor Use in National Parks}

Visitor numbers in national parks are increasing in many parts of the world, including Finland, where national parks received a 35-percent increase in the number of visits during the past five years (Metsähallitus 2017). Correspondingly, an increased effort to plan for the visitor use of parks is needed in order to guarantee the sustainability of these areas and the opportunities for quality visitor experiences (Newsome, Moore and Dowling 2013). A widely applied planning framework developed to manage outdoor recreation within natural areas, which is also applied in Finland, is called Limits of 
Acceptable Change (LAC). This framework gives guidance on what environmental and social conditions are acceptable, and about management actions that should be implemented to meet the outlined standards (McCool 1994; Kajala, Erkkonen and Perttula 2004).

To assist the planning of visitor use in parks, park organisations need information on the users of these areas. Therefore, many park organisations employ monitoring, which is the systematic gathering and analysis of data on the natural environment and its visitors over time (Newsome, Moore and Dowling 2013). The most common types of visitor monitoring are counting visits or visitors, categorising visitor characteristics, visit characteristics and visitor outcomes (Griffin et al. 2010). From a geographical perspective, the distribution and flow of visitors in space and time is key information in planning for visitor use in parks, but this information is often "sketchy at best" due to the limitations of monitoring techniques (Cole and Daniel 2003, 269). Recently, there has been increasing interest in using social media to support park management. Data such as geographically and temporally tagged images is continuously generated by digital devices and can be used to model visitor flows in parks (Orsi and Geneletti, 2013; Levin et al. 2015; Sessions et al. 2016; Tenkanen et al. 2017; Walden-Schreiner et al. 2018). However, at present these methods are also used mainly by researchers and are not integrated into the visitor monitoring that is conducted by park organisations.

In Finland, visitor monitoring relies on a well-established visitor survey procedure. Structured surveys are implemented every five years as self-administered, on-site surveys in all national parks to provide comprehensive information on visitors and their experiences, such as motives for visiting and level of satisfaction (Erkkonen and Sievänen 2001). However, this information is not collected in a location-specific 
manner, and therefore the PPGIS approach has potential to provide a new type of information for the purpose of planning for the visitor use of parks.

\subsection{PPGIS in National Park Planning}

PPGIS methods have developed since the mid-1990s, when the traditionally expertdriven Geographic Information Systems started to be utilised for social scientific purposes (Dunn 2007; Panek 2016). Since then, an extensive range of methods have been used to systematically capture and measure the spatial distribution of place values, activities, experiences, preferences and other perceptual attributes, described in an increasing number of published studies (Brown and Kyttä 2014; Brown and Fagerholm 2016). Applying PPGIS is considered recommendable for areas that should be managed with the aim of integrating the full range of values the public holds for the lands, like national forests and parks (Brown and Reed 2009; Brown and Kyttä 2014). The benefit of the PPGIS method is its capacity to capture the subjective values people associate with specific place, in a location-specific manner (Seymour et al. 2010; van Riper and Kyle 2014).

The techniques to carry out PPGIS studies have varied from paper maps to digital mapping. In its simplest form PPGIS data is used to identify distribution patterns of mapped attributes, but more sophisticated analysis procedures have been developed as well (Brown and Reed 2012a; Brown and Reed 2012b; Sherrouse, Semmens and Clement 2014; van Riper et al. 2017). The way place-based data have been collected and analysed has depended on the aims of each particular PPGIS case study. The implementation of an ongoing place-based monitoring programme in national parks can potentially require different types of data collection and analysis methods, which makes studying managers' views on collecting and analysing PPGIS data important.

Common to all PPGIS studies is the need to symbolically represent spatial 
attributes or spatial markers of interest on a map. In the context of outdoor recreation in national parks or related areas, researchers have mapped visit outcomes such as learning and solitude (Brown and Weber 2011; Pietilä 2017), the health benefits of outdoor recreation (Brown, Schebella and Weber 2014), activities in which visitors participate (Brown and Weber 2011; Munro et al. 2017), and the motives for undertaking a certain activity (Wolf et al. 2015). Researchers have also been interested in mapping visitors' perceptions of the negative impacts of tourism (Brown and Weber 2011; Scolozzi et al. 2014; Pietilä and Fagerholm 2016; Barnett et al. 2016), the conflict potential between users or different values (Wolf, Brown and Wohlfart 2017; Moore et al. 2017) and mapping the place-specific factors that affect visitor satisfaction (Pietilä and Kangas 2015).

Although a rather wide range of attributes have been examined by academics, no assessments have been done as to how different spatial attributes succeed in carrying out their goal of informing "decisions about place” (Brown and Kyttä 2014, 130). Brown and Weber $(2011,13)$ have highlighted that the process of conducting a PPGIS study in parks should begin with planners and managers together discussing the potential application of the data. In addition to co-planning PPGIS studies with managers of public lands, retrospective evaluations are similarly important when aiming to develop methods attractive also to the relevant public agencies. Outlining effective practices for using PPGIS in contexts such as national park planning is also important as PPGIS must not only have decision-support value but also be cost effective (due to limited agency budgets for human dimensions research) and approach that can be applied (Beeco and Brown 2013).

\section{Material and Methods}

This research was based on semi-structured interviews with representatives from the 
Parks and Wildlife Finland unit of Metsähallitus. The population targeted for these interviews were working in management and planning. We applied purposive sampling to select the interviewees and conducted interviews until the data reached saturation. Ten employees were interviewed, six of whom had the title of "manager" and four "planner". For convenience, we refer to all the interviewees as managers throughout the study. The interviews were conducted with employees working in a specific geographic unit, the Ostrobothnia Regional Unit, which is one of the three regional units of Parks and Wildlife Finland (Figure 1). In addition to the interviewees working in the Ostrobothnia Regional Unit, one interviewee who worked outside this geographical area was included in the study due to her knowledge of developing of the nation-wide visitor survey method. Most of the managers that we interviewed for this study had several years of experience working in visitor management duties in Parks and Wildlife Finland. Many of them had also worked in several different capacities within the organisation before their current position.

We conducted the interviews in September and October 2017 as face-to-face interviews, excluding two interviews which were conducted via telephone. The interviews focused on the themes of the quality of visitor experiences, opportunities for recreation, the characteristics and behaviour of park visitors, challenges of managing visitors in parks, and the current state of information related to visits to parks. In addition, we asked the managers to evaluate the usefulness and benefits of place-based information on visitor experiences, based on six thematic maps (Appendix 1) representing visitors' perceptions in Oulanka National Park, one of the parks within the Ostrobothnia Regional Unit. As these maps presented experiences in Oulanka National Park, it was natural that the interviews were conducted in the Ostrobothnia Regional Unit, which is responsible for the management of this park. 
We mailed the maps to the interviewees before the interviews and provided them paper copies during the interviews. The maps depicted the spatial distributions of use, visitor experiences, special places, visitor perceptions of the negative impacts of tourism (such as littering or crowding), sites where visitors felt unsafe, and development needs regarding the park's infrastructure. The maps were created using ArcMap 10.3 software based on spatial data collected in Oulanka National Park in 2014 (Pietilä and Fagerholm 2016; Pietilä 2017). The data was collected in collaboration with Parks and Wildlife Finland using an internet-based PPGIS survey that was attached to the institutional visitor survey. Out of 756 participants in the visitor survey, 170 participated in the PPGIS survey. Most of the study participants were Finns with previous experiences of visiting Oulanka National Park. Around half of the respondents were female, had higher education, and were over 45 years old.

The interviews were conducted in Finnish and lasted between 45 and 90 minutes. After receiving the interviewees' consent we audio-taped the interviews and transcribed them subsequently. The written data were analysed using thematic content analysis. Based on the research questions, we first coded the data into three themes: (1) the means of planning for the visitor use of parks and role of place-based information, (2) ways to implement place-based monitoring, and (3) the attitudes towards placebased planning practices. After this, subthemes were constructed based on the literature and on the data. All quotes in this paper were translated from Finnish into English and anonymised to protect the interviewees' confidentiality.

[Figure 1 near here] 


\section{Results}

\subsection{Planning the Visitor Use of National Parks and the role of place-based}

\section{information}

The way the managers talked about visitor experiences and their task of creating recreation opportunities reflected that their main duty with respect to managing the visitor use of parks is to geographically coordinate visitors between and within the parks, and to optimise the site conditions that visitors encounter. Foremost, most managers considered that their duty is to direct visitors to sites which can best satisfy visitors' expected needs. This was well exemplified by one manager who said, "we are the ones that say where you should go. If you have decided to visit Oulanka National Park, we advise where in that park you should go". In addition, a few interviewees also raised the need to coordinate visitors inside the individual parks. One manager related that it was previously easier to coordinate activities between parks, "but as the demand in general is growing, there will always be those who will not change destinations and therefore we need to start creating opportunities for, say, mountain biking in Oulanka National Park too".

A few managers also raised the need to geographically coordinate the visitor use of parks to prevent conflicts between different user groups. These managers were sensitive to the encounters between different user groups because they had noted that the likelihood for conflicts had increased along with the number of activities practised in the parks. A comment by one interviewee explains well the attitude that many managers had:

Depending on how much we want to optimise visitor experiences, we need more research to understand how, say, hikers experience encounters with bikers in certain sites. We do need to think about how to locate different activities so that we can optimise visitor experiences. 
Coordinating different kinds of use successfully was seen as important, as managers had a strong will to provide different kinds of activities and "ways to enjoy nature" in the parks, in contrast to the formerly dominant tendency to restrict novel activities. Understanding how to prevent potential conflicts was also considered significant as one manager mentioned that implementing multi-use trails is more feasible than providing opportunities for different activities scattered around the park, which was explained to be expensive and harmful to the aim of protecting the natural environment.

Optimising site conditions was another central issue that many managers raised. Related to this, almost all the managers brought up the changing profile of visitors in parks. Managers told that their customers are older, more unfamiliar with natural conditions, and often have improper equipment. These issues were considered to increase the need for easier and more secure recreation opportunities, such as shorter and less demanding trails. In this context, a few managers discussed that place-based information on visitors' experiences could help them to better understand visitors' preferences for site management and help them manage sites more efficiently.

First, it was imagined that place-based information would help managers compare their views with customers' views on recreation conditions. This was considered an increasing issue due to the changes in customer profile, as one interviewee explained:

What the customers consider bad conditions can deviate much from what we consider bad conditions. Especially the ones [park rangers] who have been working in the parks for decades evaluate things differently than the modern hikers of today.

In addition to this type of mismatch, one interviewee reflected that the misinterpretation can also happen in the other direction: "We easily perceive some place to be a certain 
kind. If we for example get the impression that a certain place is too crowded, we assume that all the customers think that way". Second, managers considered that placebased information on visitors' perceptions could help in prioritising and pinpointing management actions. This was exemplified by one interviewee who explained:

It is hard to prioritise one construction project over another, because when you ask an individual ranger working in a particular area, of course she/he sees the most urgent issues as located within her/his area. Knowing how customers perceive these sites could therefore help in this kind of decision-making.

Another manager highlighted that it would always be "good to compare if the things that we consider important to fix are similar to what customers think". Similarly, a third manager described that "place-based data can ensure that we are investing in the right issues, or tell us that we are investing in issues where visitors don't see any problem but ignoring places which visitors feel are dangerous or in which visitors get lost”. Moreover, it was also considered that place-based information on visitors' experiences could potentially help in determining the location of the required management actions, as one interviewee explained:

The advantage of this [place-based information] is that it doesn't just say that Oulanka National Park or Pieni Karhunkierros trail is too crowded, but its shows where the problems are. The problems do not always occur throughout the trail, but it can be a matter of some certain sites.

In addition to supporting site management actions, place-based data was also considered to hold potential for improving site-specific visitor communication. All interviewees considered that one important way to influence visitor satisfaction is pre-informing visitors about the conditions that they will encounter on the spot. Therefore, one interviewee proposed that visitor communication planning could benefit from a better understanding of where visitor experiences are better than expected and where the 
management organisation has failed in providing realistic information about site conditions.

\subsection{Place-based Monitoring of Visitor Experiences}

All managers felt that they have a great deal of information on visitors due to the visitor surveys that are carried out in the parks. When the interviewees were asked if they feel that they are lacking some type of information on visitors, only one responded that the visitor surveys do not provide spatially accurate information on visitors. In contrast, an often-mentioned downside of the existing visitor survey system was that the information from the surveys is often already five or even ten years old, which is a long time span in the contemporary world where "trends come and go". In similar vein, many managers felt that the existing visitor survey system is designed more for updating statistics and evaluating the performance of Parks and Wild Life Finland rather than supporting the planning of management actions in the parks. In addition, half of the managers noted that they also get feedback from visitors through the national online feedback system, but this is very problematic because it does not specify the site that the customer feedback concerns.

As a part of the interviews, the managers were asked to evaluate the usefulness and benefits of monitoring visitor experiences using place-based techniques. Most managers agreed on the attributes that could best aid in planning the visitor use of parks, preferring those attributes that were as concrete as possible and clearly associated with planning site management actions. This was evident in comments such as "I think that these maps in the end [maps 4, 5, 6 in Appendix 1] would be easiest to utilise. The first ones [maps $1,2,3]$ require more advanced thinking ... their practicality is a bit vague." A comment by another manager supported this notion: "I can see concrete benefits to development in these three last ones [maps 4, 5, 6]. The others $[1,2,3]$ are kind of 'nice 
to know' information and can maybe guide some long-term planning, but they are not that practical." Therefore, the most preferred spatial attributes represented visitor perceptions of the negative impacts of tourism, of sites that were perceived unsafe, and of sites where the infrastructure needs development.

Managers viewed that with respect to the perceptions of the negative impacts of tourism, mapping especially littering, erosion and crowding would be valuable. The interviewees indicated that knowing how these perceptions are dispersed in the park would help them to plan suitable site management actions as well as visitor communication strategies. In addition, the managers saw that mapping the places where visitors feel unsafe could help them to make decisions such as whether to change the trail alignments, build fences or modify the information regarding these sites. Visitor perceptions of the development needs related to recreation infrastructure were likewise considered very useful for planning site management actions. One interviewee highlighted especially the need to recognise customers' input when designing the signposting of the trails. She emphasised that visitors are the experts in assessing where the signposting is appropriate and where not.

Mapping the outcomes of visiting a particular site was not perceived to be particularly useful. When the managers were shown a map of the different types of experiences visitors had had in different locations at Oulanka National Park, most of the managers had a hard time imagining how they could use this kind of information. Nevertheless, individual managers proposed that knowing the outcomes of park visits and the sites that are considered attractive could help them in preparing the park management plans and in communicating a park's attractions to visitors. In addition, one interviewee envisioned that if they were to start setting certain experiential goals for 
trails in the future, place-based measurement of visitors' experiences could help them to verify how well the realised experiences correspond with the set aims.

Related to the spatial attributes that managers considered useful to map, half of the interviewees highlighted that the national parks differ from each other significantly, and thus have different information needs with respect to supporting the planning of visitor use. Oulanka National Park, which was used to exemplify the potential of placebased data, was even considered problematic by the interviewees, as its visitor use is already a "settled" matter. As one interviewee explained: "This place-based data could be valuable in areas where you are planning the land use or envisioning the future. I mean, in cases where you don't know the visitors that well and you don't have that much data." Therefore, newly established conservation areas were mentioned as areas where mapping visitors' movement and experiences would be especially valuable.

In addition to using PPGIS tools to monitor visitor experiences, a few managers also saw potential in using PPGIS methods to indirectly monitor the state of a park's physical environment. The managers explained that much of the data that is used in evaluating the sustainability of the parks is in fact already based on visitors' perceptions. Therefore, one interviewee envisioned the possibility of "spatialising" the data that is used for evaluating the state of the parks. He saw that this could be useful, "as the currently used indicators tend to cover the reality of the state of some heavily used parts of the parks, such Pieni Karhunkierros in Oulanka National Park, which can differ significantly from the conditions in the park in general". Monitoring the state of the parks was considered vital in the context of the increasing number of visitors in the parks. This was evident in interviewee comments such as, "we are now facing serious issues caused by the increasing number of visits in many areas and we need to start thinking, what do we do now? How do we guarantee the sustainability of our parks?" 
In addition to the issue of what should be mapped, managers envisioned how place-based monitoring could best be implemented in practice. Half of the interviewed managers suggested that the best way to collect spatial information on visitor experiences would be to implement an internet application for giving location-specific feedback. One interviewee proposed that this could be connected to the existing interface for providing information on recreation services: "The Excursionmap.fi could be made bidirectional, so that the public could also provide information to managers. So, visitors could let us know if there is no firewood in the rest places and so forth." Two interviewees highlighted that visitors should have the possibility to give feedback while visiting the park. One interviewee especially emphasised that the organisation must succeed better in getting feedback from those who do not encounter the visitor centres because the visitor numbers are increasing particularly in the park areas and not in the visitor centres. For this reason, the possibility of implementing a mobile application for giving feedback on services to the park organisation was recommended by some managers.

\subsection{Attitudes towards Place-based Planning Practices}

The interviewed managers seemed to perceive that customer feedback would become increasingly important in the future, because there is less and less people working in the field and monitoring the conditions. One manager also highlighted that because the services and infrastructure in the parks are increasingly run and maintained by external entrepreneurs, the information does not flow from the field to the park managers as it used to. In addition, one interviewee pointed out that one benefit of using customers as information sources is that it saves resources, as “then the ranger doesn't need to walk the trail to confirm that, yes, the board-walk is broken there". 
The willingness to collect place-based information from visitors varied somewhat between the interviewees. However, only one interviewee was hesitant about the methods, which is illustrated by his comment: "I don't see any harm in that placebased information, but I don't know if it has any use either. It may have . . it's hard to say. In the end, is it actually useful?" Other managers seemed to be more eager to find ways to implement the methods in their visitor management practices. This was especially true of the three managers who saw that information that is presented on a map is very illustrative, one of which noted that "maps can tell those issues much better by being much more illustrative". Going beyond collecting and presenting visitor experiences on maps, some interviewed managers were so interested in the method that they envisioned that all the visitor information could be stored and analysed in a placebased manner in the same GIS software where all the other data related to the parks will soon be available. This was described by two interviewees who argued that

If we think of this current visitor survey or monitoring the numbers of visits to the parks, it would be great if the production and usage of all this information would be place-based. In the future, when we will get this new GIS software/database for the entire recreation infrastructure, it would be ideal if we could have the information from the visitor surveys and from the visitor counts built into this database, attached to the trails.

I would like to have all our information on maps! So that this kind of information [visitor experiences] would be there in our GIS databases so that we would have this kind of experiential layer available when we use our new GIS software in our planning. ... So that those issues which we've gone over [different aspects of visitor experiences] could be plotted on a map, just like that. We would see what visitors have experienced in different parts of the parks. Similarly to how we have data on endangered species that can be overlaid on the trails maps.... Our GIS database and software, as good as they are, don't allow for this kind of experiential data. 
These quotes illustrate that managers were clearly willing to adopt place-based methods in planning the visitor use of national parks.

Even though the potential of using place-based methods for monitoring purposes was acknowledged, one interviewee cautioned that "changing the monitoring method all of a sudden is not that simple, because Parks and Wildlife Finland has succeeded in collecting a unique dataset using the existing survey method”. In addition, some managers, despite their interest in the place-based methods, were also wary about adopting new methods:

We always need to consider the cost-effectiveness of these method, and the workload against the benefit of the information: this kind of information is 'very nice to know' but could we still survive without it? There is always that reality, and otherwise we are constantly under pressure to minimise.

It is a challenge, that if we want to develop our methods towards that [spatiality], we need to be able to cut down on some other methods to be able to analyse all that data. Information can also be misleading. . . . If there is an excessive amount of data which is not relevant for decision-making, the information burdens the decision-making. It is not useful, but actually harmful.

A few managers were also concerned about how their staff would handle the competencies that the place-based methods require, which came up in the comments such as

It would be a huge step in the know-how of our personnel. That they would understand the potential of the GIS methods. Likewise, there must also be some guidelines for using those methods, and these should be based on evidence and best practices. It will be a huge developmental step in our operations.

In addition to the competency requirements, the previous quote also shows the potential challenges of processing the place-based data. 


\section{Discussion}

The number of visits to national parks is increasing, which demands more efficient planning of visitor use within these areas. The PPGIS approach is said to offer opportunities to integrate visitors' experiences into the planning of national parks, but so far there has been only little evidence of formal agency adoption of the PPGIS approach (Brown 2012; Brown and Kyttä 2014; Brown and Kyttä 2018; Kahila-Tani et al. 2016). In this study we investigated the views of park managers with respect to using a place-based approach in planning.

In this study, we found that the managers of Parks and Wildlife Finland consider coordinating visitor use across and within parks as one of their main visitor management tasks. Place-based methods could promote this task by helping to define the recreation opportunities that certain areas provide, as has been suggested in previous research (Beeco and Brown 2013; Brown and Weber 2011). Coordinating visitor use in parks was also considered important in order to prevent conflicts between users, which the managers perceived as important due to the fact that the number of different activities in the parks is increasing. As the PPGIS approach can help in revealing those sites which have high conflict potential, the possibilities of using PPGIS tools to map realised conflicts and conflict potential between different types of recreationists should be explored, as this in an issue that has not been widely explored in the context of national parks (Wolf et al. 2017). The interviews with managers further indicated that, in addition to conflict locations, there is a need to collect qualitative information that describes the negative encounters between users, as this is important in planning effective management actions.

The study showed that PPGIS could aid in optimising the site conditions by bringing to light the possible differences opinions that visitors and managers have as 
regards site conditions. Identifying differences in the sensitivity of managers and visitors towards various tourism-related impacts is important as wide deviations have been evidenced (Martin, McCool and Lucas 1989; Brown and Weber 2011). The particular advantage of PPGIS tools in relation to this practise is that it can show where these misinterpretations take place, and thus enable managers to target management actions to those sites which are critical for visitor satisfaction.

We also found that managers had some interest in integrating PPGIS tools in the ongoing LAC monitoring. Brown and Weber (2011) have also suggested that one potential application of PPGIS data could be the development of an ongoing, public park monitoring programme that focuses on impacts such as noise, litter, wildlife and water. Place-based data on visitors' perceptions of park conditions could improve the LAC monitoring process by highlighting sites within individual parks where the limits of acceptable change are exceeded, even in the absence of alarming signs in park-scale indicators. This is important as previous studies have also evidenced that visitors' notions of what is acceptable within a certain context regarding tourism impacts differs according to the specific location (Hammitt and Cole 1998; Vaske and Donnelly 2001; Vaske, Donnelly and Lehto 2002; Pietilä and Fagerholm 2016). However, the challenge related to using PPGIS data in relation to LAC monitoring is that PPGIS methods are highly sensitive to sampling design and participant characteristics (Brown 2017). This can be problematic when the purpose of the monitoring is to compare the state of park conditions across time and, therefore, the collected data should at each interval represent all park users.

In addition to exploring how PPGIS could serve certain management tasks, we studied which spatial attributes managers consider relevant to map, as well as how they would prefer the mapping of visitor experiences be carried out. We found that managers 
prioritised mapping concrete spatial attributes that are closely linked to planning site management actions. These spatial attributes differ from those that are commonly mapped in PPGIS studies because most PPGIS studies have focused on mapping rather abstract attributes such as spiritual or life sustaining values, or ecosystem services (Brown and Kyttä 2014; Brown and Fagerholm 2015). We consider that this difference results from the narrow scope of our study: we intentionally asked the managers to evaluate the usefulness of the attributes for planning the visitor use of parks. When broadening the perspective to overall park management, including the ideal of including all different stakeholders in the planning, the importance of other types of attributes would probably arise.

Mapping visitor experiences can be technically carried out in multiple ways. The interviews showed that managers prefer a place-based internet application in which customers could give feedback on the site conditions while visiting the park, e.g. mobile phones applications are considered useful. When integrated well into planning processes this can compensate for the disadvantage of visitor surveys, that is, that they are a slow channel for bringing to light visitors' perceptions. In addition, it could make it easier for managers to identify where the potential problems are occurring, which was considered a key problem of the national feedback system. Previous studies have also encouraged mapping visitor experiences on the spot to diminish the inaccuracy of spatial data that can result from the difficulty of recalling experiences after the visit (e.g. Pietilä and Kangas 2015). Still, there are only a few studies which investigate the potential of collecting visitor experiences in the field using mobile phones (Doherty, Lemieux and Canally 2014; Birenboim 2016).

This study showed that the managers of Parks and Wildlife Finland are eager to understand customers' experiences and wish to include visitor perspectives (e.g. in the 
planning of new national parks). Therefore, the results are not in line with the suggestions that regional and environmental planning agencies have not adopted PPGIS methods into their planning processes because of a lack of institutional commitment to public participation and consultation in general (Brown 2012; Brown and Kyttä 2014). As limited resources was an often-mentioned issue, new ways to engage with visitors, who may be specialists in their activities, in the planning of recreation services hold much promise. However, even though the managers showed great interest in placebased participation methods, some reservations to adopting PPGIS methods arose. The mentioned challenges seem to relate to handling and taking advantage of the already existing visitor data, and the possibility of integrating the "new type of data" with the existing monitoring processes that have received an institutionalised position.

Another organisational barrier for adapting PPGIS methods is said to be the lack of skills to use the data effectively (Kahila-Tani et al. 2016). Even though only a few managers in our study raised this issue, the challenges related to analysing place-based data, beyond creating visual presentations, could become more acute when actually faced with handling and integrating PPGIS data into planning processes. Researchers have developed promising tools and methods, such as values compatibility analysis (VCA) (Brown and Reed 2012a), SolVES (Sherrouse, Semmens and Clement 2014; van Riper et al. 2017) and social landscape metrics (Brown and Reed 2012b), to analyse and quantify mapped forest and social values in a place-based manner. These metrics have indeed become a common method for quantifying PPGIS data (e.g. Hausner, Brown and Lægreid 2015; Pietilä and Fagerholm 2016). However, as these tools are primarily developed for analysing social values, there is an additional need to develop the tools to support the analysis of those attributes that serve planning for outdoor recreation. For this purpose, and in particular to carry out straightforward operational use in planning 
organisations, there is a need to develop professional analysis interfaces that can automatically quantify attributes, i.e. create indicators, such as those related to conflict potential, danger, or infrastructure development needs.

The limitations of this study relate to the maps used as supplementary material in the interviews. These maps presented examples of different types of experiential attributes that can be mapped through PPGIS in the context of a national park.

However, the chosen examples and the way these maps were illustrated may have influenced how they were interpreted by the managers. In addition, the fact that the experiences on the maps were presented only using point data without further data processing could have influenced the relevance of the PPGIS approach. If the data had been presented in a more quantified form, the managers' responses might have been different.

We believe that the spatial attributes that the managers found useful to map in this study would also help park organisations around the world to make their planning for visitor use more effective. However, we consider that the managers' attitudes towards place-based data and the obstacles to applying the PPGIS approach can only be generalised across the Finnish park organisation. This is because each park organisation has its own organisational culture and visitor monitoring practices, causing differences in how the potential of the PPGIS approach is seen. Therefore, in order to be able to compare and discuss possible differences in the needs and attitudes towards place-based data, we encourage studying managers' attitudes towards the PPGIS approach also in other contexts.

\section{Conclusions}

In this study, we assessed the potential of the PPGIS approach in the context of planning the visitor use of Finnish national parks by exploring manager perceptions. 
This study shows that place-based data on visitor experiences could help in coordinating visitors and in optimising site management. It also encourages implementing a placebased online application to collect visitors' perceptions of site conditions to help managers in planning management actions. Our study revealed that the hesitance that public agencies have towards adopting PPGIS tools, at least in the context of Finnish National Park management, are not related to a reluctance towards public participation. Managers in general are willing to use PPGIS tools, but because the organisation already has a great deal of data on its visitors, it is uncertain as to where the place-based data could be most beneficial and worth investing in. This study increased knowledge on managers' needs with respect to PPGIS. This knowledge will help to further develop these approaches and thereby make the approaches more attractive to organisations outside of academia that are contemplating PPGIS case studies to serve the planning of visitor use of parks, and ultimately, integrating PPGIS tools into planning processes.

\section{References}

Barnett, Allain J., Melanie G. Wiber, Michael P. Rooney, and Donna G. Curtis Maillet. 2016. "The role of public participation GIS (PPGIS) and fishermen's perceptions of risk in marine debris mitigation in the Bay of Fundy, Canada." Ocean \& Coastal Management 133: 85-94.

Beeco, J. Adam, and Greg Brown. 2013. "Integrating space, spatial tools, and spatial analysis into the human dimensions of parks and outdoor recreation." Applied Geography 38: 76-85.

Birenboim, Amit. 2016. "New approaches to the study of tourist experiences in time and space." Tourism Geographies 18 (1): 9-17.

Brown, Greg, and Delene Weber. 2011. "Public Participation GIS: A new method for national park planning." Landscape and urban planning 102 (1): 1-15.

Brown, Greg, and Marketta Kyttä. 2014. "Key issues and research priorities for public participation GIS (PPGIS): A synthesis based on empirical research." Applied Geography 46: 122-136. 
Brown, Greg, and Marketta Kyttä. 2018. "Key issues and priorities in participatory mapping: Toward integration or increased specialization?" Applied Geography 95: $1-8$.

Brown, Greg, and Nora Fagerholm. 2015. "Empirical PPGIS/PGIS mapping of ecosystem services: a review and evaluation." Ecosystem Services 13: 119-133.

Brown, Greg, and Pat Reed. 2009. "Public participation GIS: a new method for use in national forest planning." Forest science 55 (2): 166-182.

Brown, Greg, and Pat Reed. 2012a. "Values compatibility analysis: integrating public values in a forest planning decision support system." Applied spatial analysis and policy 5 (4): 317-332.

Brown, Greg, and Pat Reed. 2012b. "Social landscape metrics: measures for understanding place values from public participation geographic information systems (PPGIS)." Landscape Research 37 (1): 73-90.

Brown, Greg, Delene Weber, and Kelly De Bie. 2014. "Assessing the value of public lands using public participation GIS (PPGIS) and social landscape metrics." Applied Geography 53: 77-89.

Brown, Greg, Morgan Faith Schebella, and Delene Weber. 2014. "Using participatory GIS to measure physical activity and urban park benefits." Landscape and Urban Planning 121: 34-44.

Brown, Greg. 2012. "Public Participation GIS (PPGIS) for regional and environmental planning: Reflections on a decade of empirical research." Journal of Urban and Regional Information Systems Association 25 (2): 7-18.

Brown, Greg. 2017. "A review of sampling effects and response bias in internet participatory mapping (PPGIS/PGIS/VGI)." Transactions in GIS 21 (1): 39-56.

Cole, David N., and Terry C. Daniel. 2003. "The science of visitor management in parks and protected areas: from verbal reports to simulation models." Journal for Nature Conservation 11 (4): 269-277.

De Valck, J., Broekx, S., Liekens, I., De Nocker, L., Van Orshoven, J. and Vranken, L., 2016. "Contrasting collective preferences for outdoor recreation and substitutability of nature areas using hot spot mapping". Landscape and Urban Planning, 151, 64-78. 
Doherty, Sean T., Christopher J. Lemieux, and Culum Canally. "Tracking human activity and well-being in natural environments using wearable sensors and experience sampling." Social Science \& Medicine 106 (2014): 83-92.

Dunn, Christine E. "Participatory GIS—a people's GIS?. 2007. "Progress in human geography 31(5): 616-637.

Erkkonen, Joel, and Tuija Sievänen. 2001. Kävijätutkimusopas [Guide for conducting Visitor survey]. Nature Protection Publications of Metsähallitus. Series B 62. Vantaa: Metsähallitus.

Frost, Warwick, and Colin Michael Hall, eds. 2009. Tourism and national parks: International perspectives on development, histories, and change. London: Routledge.

Garcia-Martin, M., Fagerholm, N., Bieling, C., Gounaridis, D., Kizos, T., Printsmann, A., Müller, M., Lieskovský, J. and Plieninger, T., 2017. "Participatory mapping of landscape values in a Pan-European perspective". Landscape Ecology, 32(11), 2133-2150.

Griffin, Tony, Sue Moore, Gary Crilley, Simon Darcy, and Stephen Schweinsberg. 2010. Protected area management: collection and use of visitor data. Vol. 1: Summary and recommendations. Gold Coast: CRC for Sustainable Tourism Pty Ltd.

Hausner, Vera Helene, Greg Brown, and Eiliv Lægreid. 2015. "Effects of land tenure and protected areas on ecosystem services and land use preferences in Norway." Land Use Policy 49: 446-461.

Ives, C.D. and Kendal, D., 2014. "The role of social values in the management of ecological systems". Journal of environmental management, 144, 67-72.

Kahila-Tani, Maarit, Anna Broberg, Marketta Kyttä, and Taylor Tyger. 2016. "Let the citizens map - public participation GIS as a planning support system in the Helsinki master plan process." Planning Practice \& Research 31 (2): 195-214.

Kajala, Liisa, Erkkonen, Joel, and Minttu Perttula. 2004. 'Measures for developing sustainability of nature tourism in protected areas". In Policies, Methods and Tools for Visitor management, Proceedings of the Second International Conference on Monitoring and Management of Visitor Flows in Recreational and Protected areasedited by Sievänen, Tuija, Erkkonen, Joel, Jokimäki, 
Jukka, Saarinen, Jarkko, Tuulentie, Seija and Eija Virtanen, 241-246. Working Papers of the Finnish Forest Research Institute.

Korpilo, S., Virtanen, T., Saukkonen, T. and Lehvävirta, S., 2018. "More than A to B: Understanding and managing visitor spatial behaviour in urban forests using public participation GIS.” Journal of environmental management, 207, 124133.

Levin, N., Kark, S. and Crandall, D., 2015. "Where have all the people gone? Enhancing global conservation using night lights and social media." Ecological Applications, 25(8), 2153-2167.

Martin, Steven R., Stephen F. McCool, and Robert C. Lucas. 1898. "Wilderness campsite impacts: Do managers and visitors see them the same?." Environmental Management 13 (5): 623-629.

McCool, Stephen F. 1994. "Planning for sustainable nature dependent tourism development: the limits of acceptable change system." Tourism recreation research 19 (2): 51-55.

Metsähallitus. 2017. "Visitation numbers in protected areas of Finland.“ Metsähallitus. Accessed October 5 2017. http://www.metsa.fi/web/en/visitationnumbers

Moore, Susan A., Greg Brown, Halina Kobryn, and Jennifer Strickland-Munro. 2017. "Identifying conflict potential in a coastal and marine environment using participatory mapping." Journal of Environmental Management 197: 706-718.

Munro, Jennifer, Halina Kobryn, David Palmer, Sam Bayley, and Susan A. Moore. 2017. "Charting the coast: spatial planning for tourism using public participation GIS." Current Issues in Tourism: 1-19.

Newsome, David, Susan A. Moore, and Ross Kingston Dowling. 2012. Natural area tourism: Ecology, impacts and management. Vol. 58. Channel view publications.

Orsi, F. and Geneletti, D., 2013. "Using geotagged photographs and GIS analysis to estimate visitor flows in natural areas." Journal for nature conservation, 21(5), 359-368.

Palomo, Ignacio, Berta Martín-López, Pedro Zorrilla-Miras, David García Del Amo, and Carlos Montes. "Deliberative mapping of ecosystem services within and around Doñana National Park (SW Spain) in relation to land use change." Regional environmental change 14, no. 1 (2014): 237-251. 
Pánek, Jiř́i. 2016. "From mental maps to GeoParticipation." The Cartographic Journal 53 (4): 300-307.

Pietilä, Miisa, and Katja Kangas. 2015. "Examining the relationship between recreation settings and experiences in Oulanka National Park-A spatial approach." Journal of Outdoor Recreation and Tourism 9: 26-36.

Pietilä, Miisa, and Nora Fagerholm. 2016. "Visitors' place-based evaluations of unacceptable tourism impacts in Oulanka National Park, Finland." Tourism Geographies 18 (3): 258-279.

Pietilä, Miisa. 2017. "Do Visitor Experiences Differ Across Recreation Settings? Utilizing Geographical Information Systems to Study the Setting-Experience Relationship.” Visitor Studies 20 (2): 187-201.

Scolozzi, Rocco, Uta Schirpke, Carlo Detassis, Sabah Abdullah, and Alessandro Gretter. 2015. "Mapping alpine landscape values and related threats as perceived by tourists." Landscape research 40 (4): 451-465.

Sessions, C., Wood, S.A., Rabotyagov, S. and Fisher, D.M., 2016. "Measuring recreational visitation at US National Parks with crowd-sourced photographs." Journal of environmental management, 183, 703-711.

Seymour, Eloise, Allan Curtis, David Pannell, Catherine Allan, and Anna Roberts. 2010. "Understanding the role of assigned values in natural resource management." Australasian Journal of Environmental Management 17 (3): 142-153.

Sherrouse, Benson C., Darius J. Semmens, and Jessica M. Clement. 2014. "An application of Social Values for Ecosystem Services (SolVES) to three national forests in Colorado and Wyoming." Ecological Indicators 36: 68-79.

Strickland-Munro, Jennifer, Halina Kobryn, Greg Brown, and Susan A. Moore. 2016. "Marine spatial planning for the future: Using Public Participation GIS (PPGIS) to inform the human dimension for large marine parks." Marine Policy 73: 15-26.

Tenkanen, H., Di Minin, E., Heikinheimo, V., Hausmann, A., Herbst, M., Kajala, L. and Toivonen, T., 2017. "Instagram, Flickr, or Twitter: Assessing the usability of social media data for visitor monitoring in protected areas." Scientific reports, 7(1). 1-11. 
van Riper, Carena J., and Gerard T. Kyle. 2014. "Capturing multiple values of ecosystem services shaped by environmental worldviews: a spatial analysis." Journal of environmental management 145: 374-384.

van Riper, Carena J., Gerard T. Kyle, Benson C. Sherrouse, Kenneth J. Bagstad, and Stephen G. Sutton. 2017. "Toward an integrated understanding of perceived biodiversity values and environmental conditions in a national park." Ecological Indicators 72: 278-287.

Vaske, J. J., and Donnelly, M. P. 2001. Social impact indicators and standards at the Columbia Icefield (HDNRU Report No. 47). Fort Collins: Colorado State University.

Vaske, J. J., Donnelly, M. P., \& Lehto, X. 2002. Visitor crowding and normative tolerances at congested areas of Rocky Mountain National Park (HDRNU Report No. 50). Fort Collins: Colorado State University.

Walden-Schreiner, C., Leung, Y.F. and Tateosian, L., 2018. "Digital footprints: Incorporating crowdsourced geographic information for protected area management". Applied Geography, 90, 44-54.

Wolf, Isabelle D., Greg Brown, and Teresa Wohlfart. 2017. "Applying public participation GIS (PPGIS) to inform and manage visitor conflict along multiuse trails." Journal of Sustainable Tourism, 1-26.

Wolf, Isabelle D., Teresa Wohlfart, Greg Brown, and Abraham Bartolomé Lasa. 2015. "The use of public participation GIS (PPGIS) for park visitor management: A case study of mountain biking." Tourism Management 51: 112-130. 
Appendix 1. The supplementary map material that was utilized in the interviews.

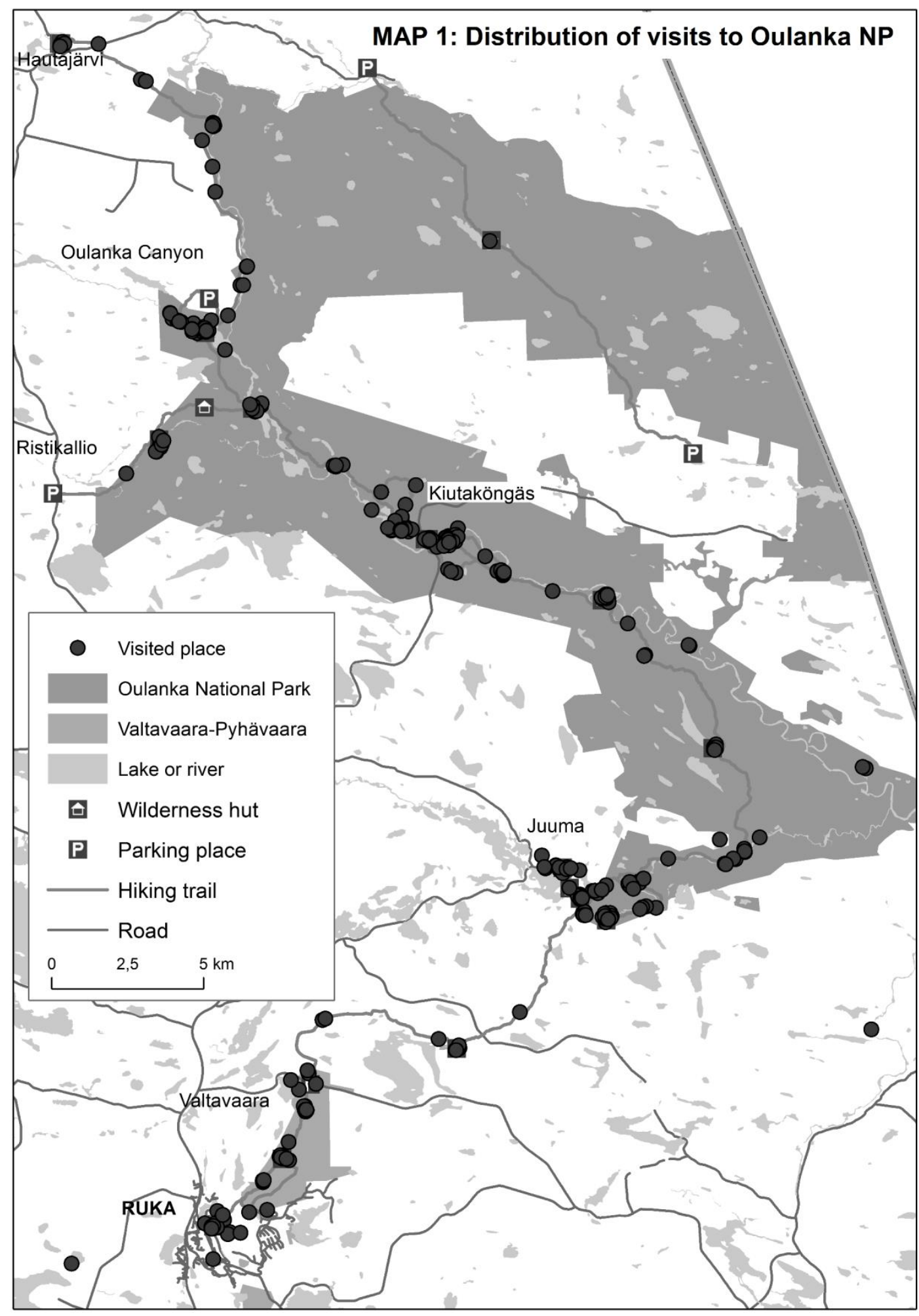


MAP 2: Distrubution of different types of visitor experiences

PHYSICAL WELLBEING

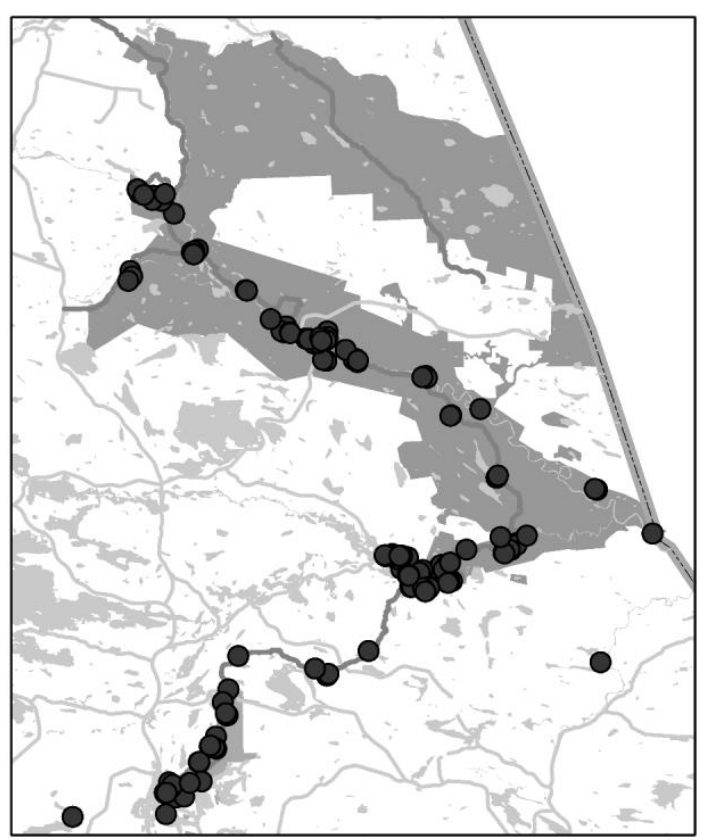

NOSTALGIA

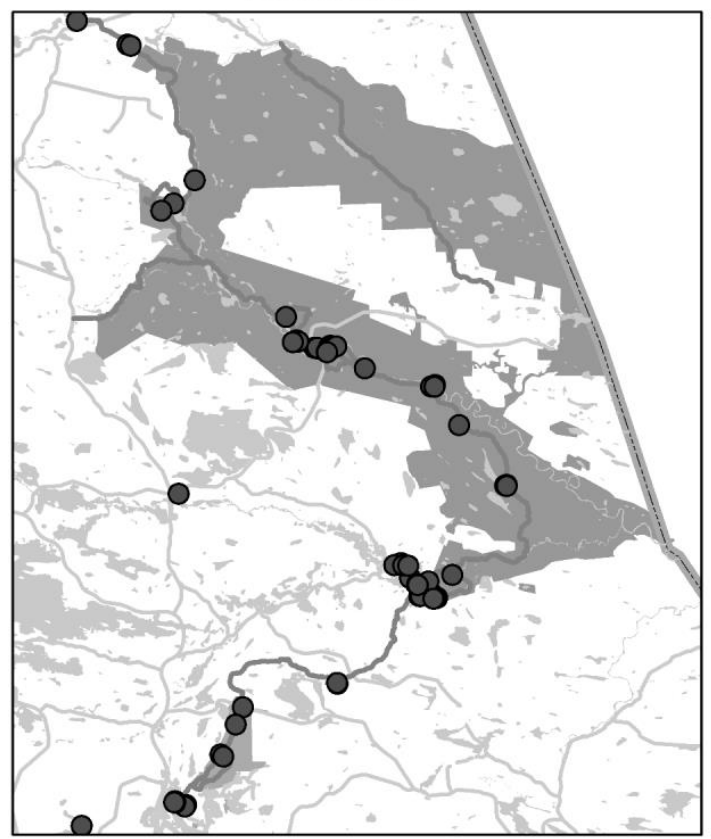

RELAXATION

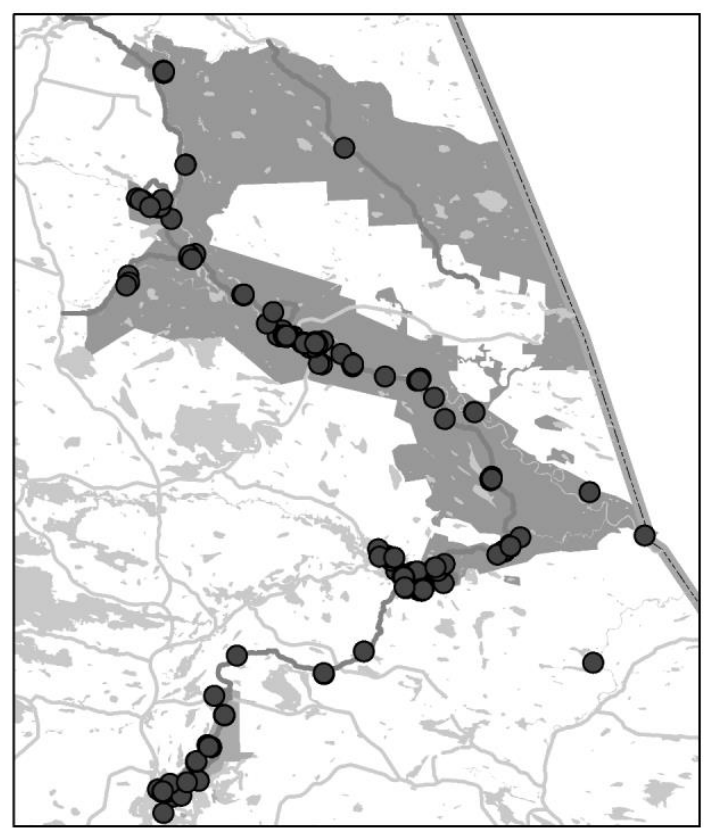

SOLITUDE

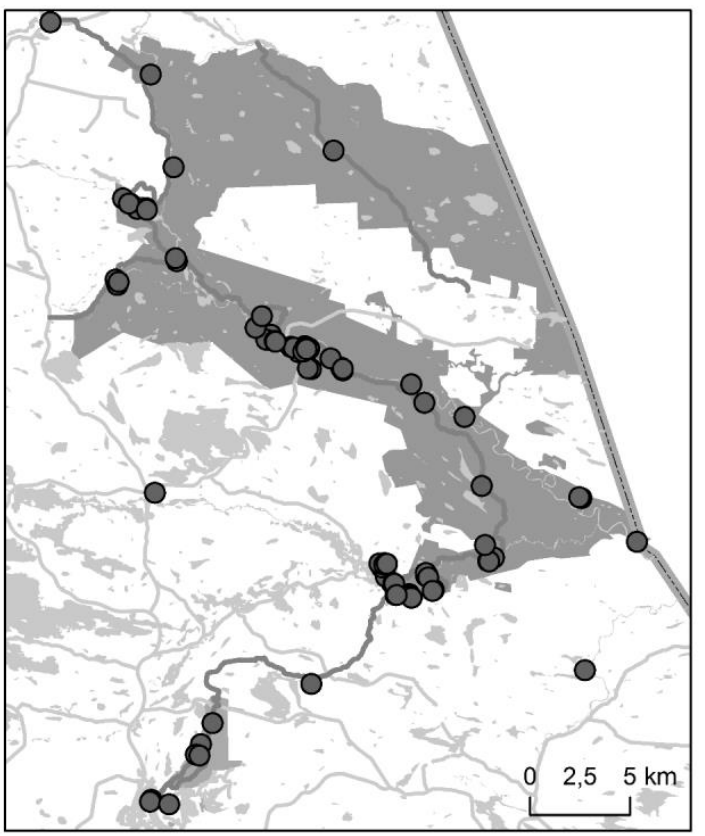

Oulanka National Park Hiking trail

Valtavaara-Pyhävaara Road

Lake or river 


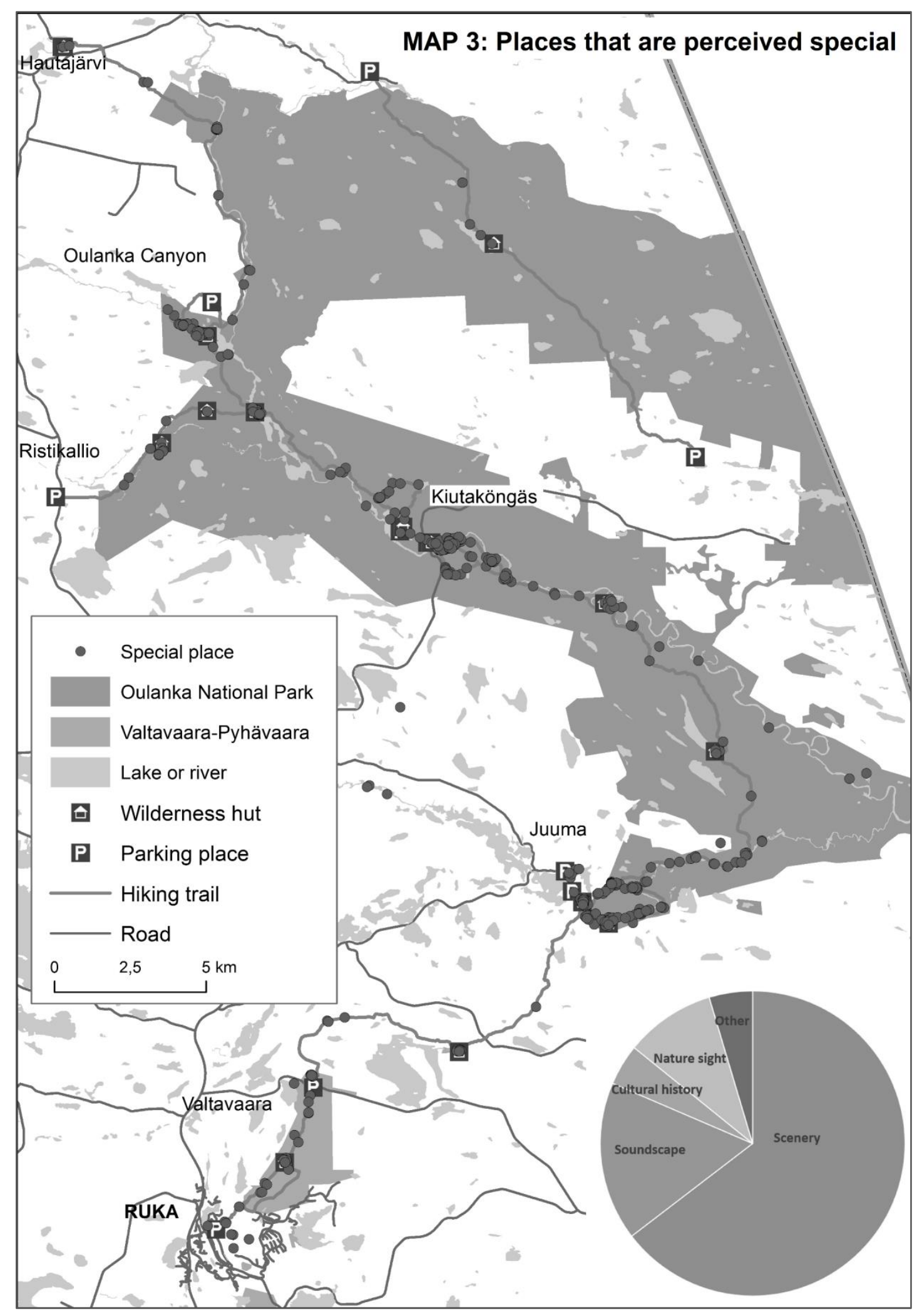



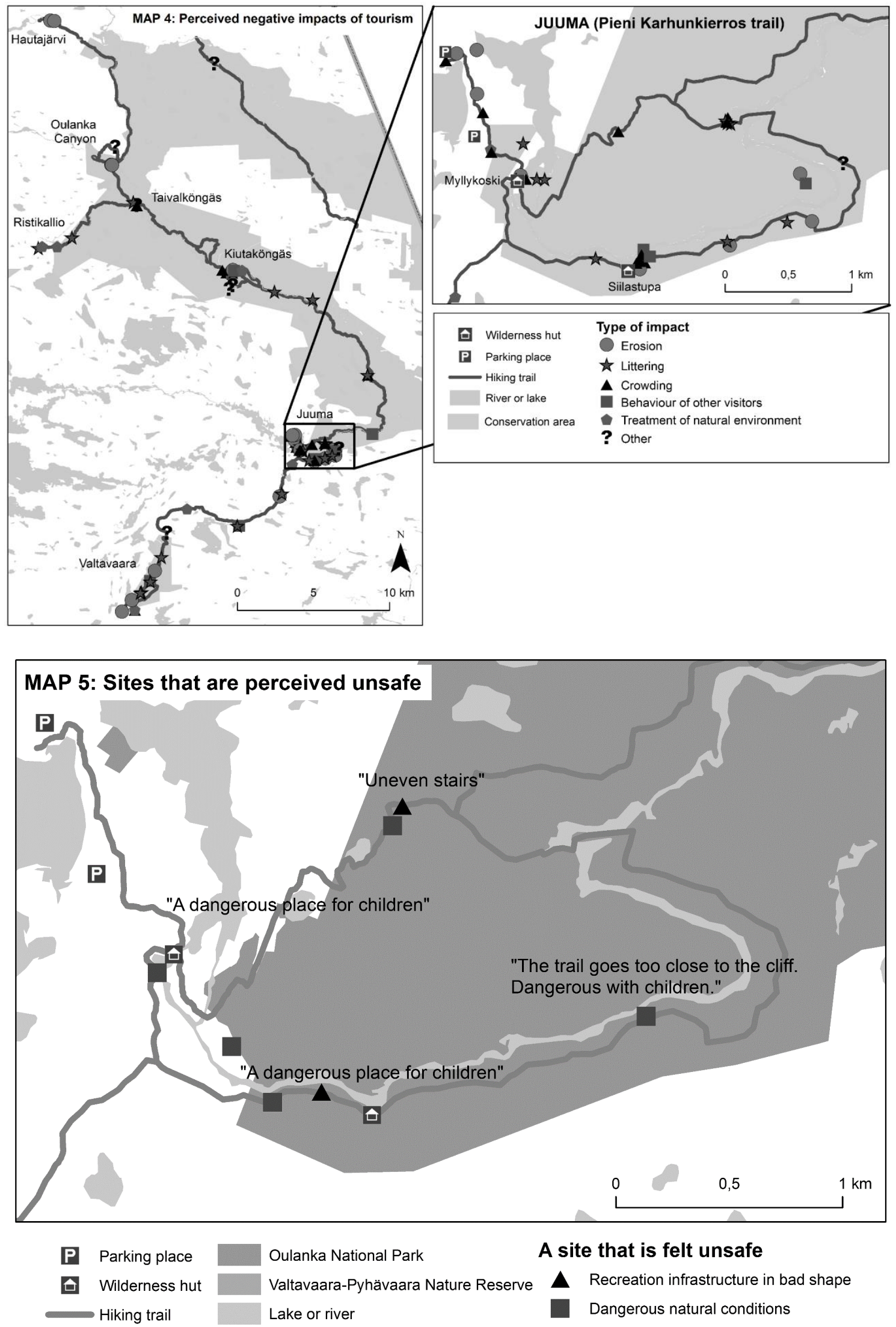

Oulanka National Park

A site that is felt unsafe

A Recreation infrastructure in bad shape

Valtavaara-Pyhävaara Nature Reserve

Lake or river

Dangerous natural conditions 


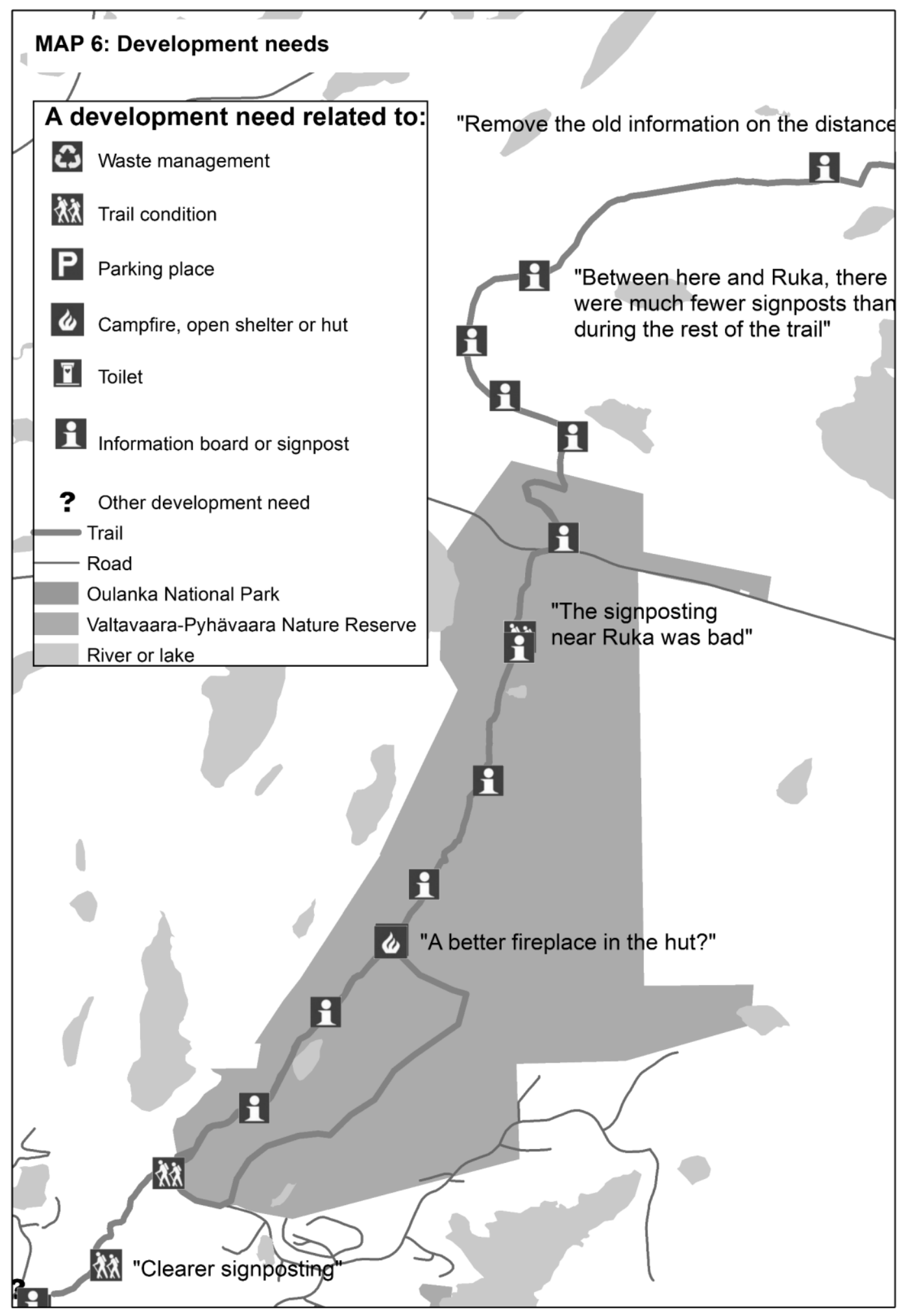




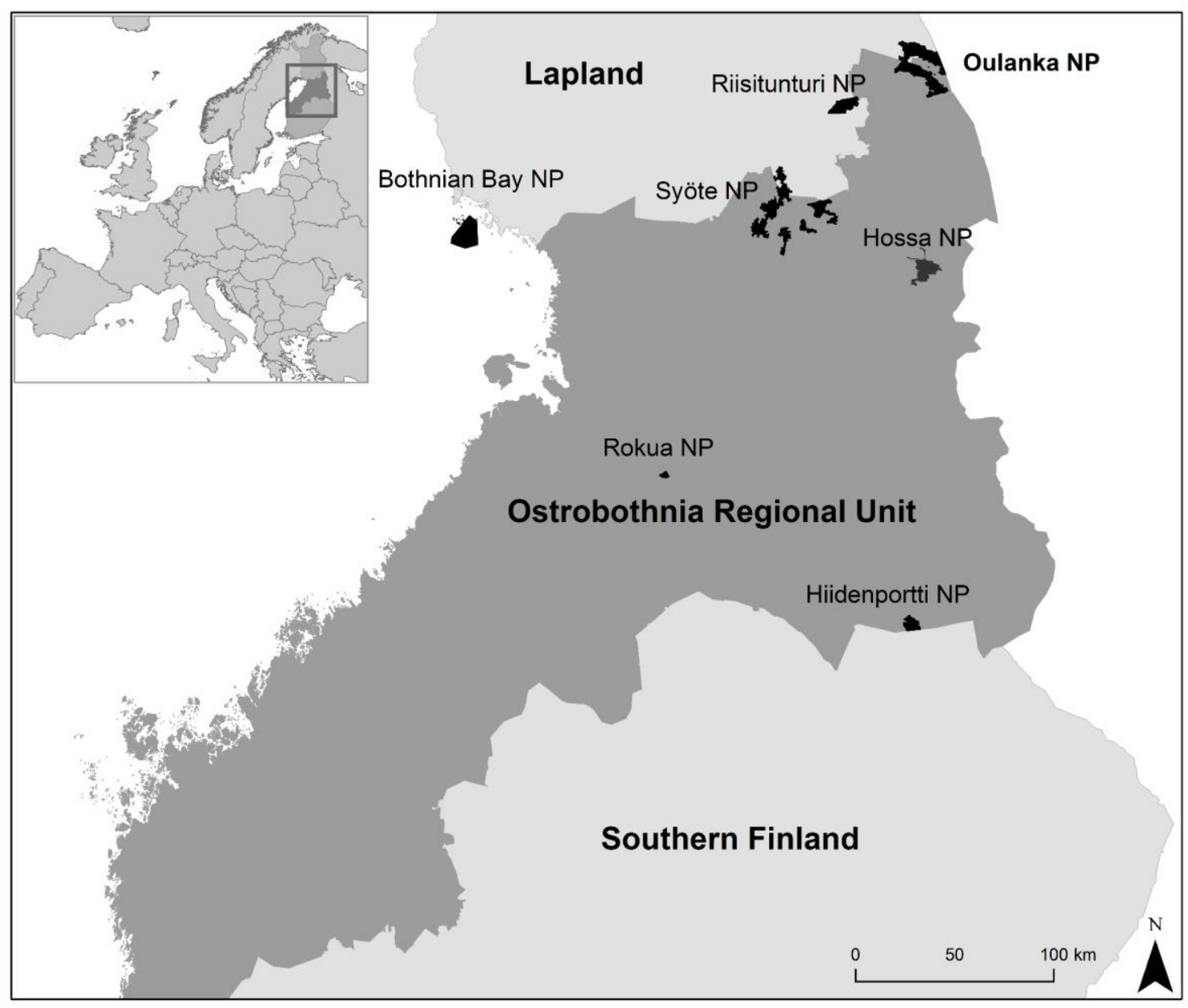

Figure 1. The National Parks (NP) managed by the Ostrobothnia Regional Unit of the Parks and Wildlife Finland, Metsähallitus. 